\title{
Bam Archaeological Mission: a new archaeological research programme in Kerman Province, Iran
}

Benjamin Mutin ${ }^{1,2, *} \&$ Omran Garazhian ${ }^{3}$

The Bam Archaeological Mission aims to investigate ancient settlement in the Bam-Narmashir region of Iran. Preliminary survey has identified over 200 new archaeological sites, with renewed excavation at the key site of Tell-e Atashi revealing structural evidence of Neolithic occupation.

\section{Introduction}

The Bam Archaeological Mission (BAM) in the Bam-Narmashir region, in the southwestern margin of the Lut Desert (Kerman, Iran), began in 2016 (Figure 1). The BAM's main objective is to investigate the ancient settlement in this area-its evolution, cultural links and relationship to environmental changes. Beyond the Bam region, this research aims to contribute to the study of ancient south-eastern Iran, and, more broadly, to the understanding of the dispersal and interaction of people, cultures and technologies across Middle- and South Asia during pre- and proto-history. The creation of BAM was prompted by the discovery of proto-historical sites after the infamous 2003 earthquake: Chalcolithic sites in Bam's western periphery and Neolithic-Chalcolithic sites east of Bam in Darestan, including the Neolithic site of Tell-e Atashi (Adle 2006; Garazhian 2009; Soleimani et al. 2016). In its first field season (2016), the BAM surveyed the region. In 2017, the mission opened test trenches at Tell-e Atashi.

\section{First field season}

In 2016, the BAM surveyed along the area's main west-east river system for about $60 \mathrm{~km}$ between Darzin and Darestan (Figure 1). This recorded over 200 archaeological sites with Palaeolithic to Islamic remains, including many Neolithic and Late Chalcolithic sites. Six sites yielded Middle Palaeolithic lithics. We recorded more than 80 Neolithic sites, including approximately 35 aceramic sites. The Neolithic pottery is a plain, vegetaltempered ware, comparable to other Iranian Neolithic plain vessels, such as at Tepe Yahya,

1 Harvard University, Department of Anthropology, Peabody Museum, 11 Divinity Avenue, Cambridge MA 02138, USA

2 French National Center for Scientific Research, UMR7041, Archéologies et Sciences de l'Antiquité, Archéologie de l'Asie centrale, Maison Archéologie \& Ethnologie, René Ginouvès, 21, allée de l'université, F-92023 Nanterre Cedex, France

3 University of Neyshabur, Department of Archaeology, Adib Boulevard, Neyshabur, Khorasan Razavi, 9319774400, Iran

* Author for correspondence (Email: benmutin@gmail.com)

(C) Antiquity Publications Ltd, 2018

ANTIQUITY 92 363, e8 (2018): 1-7 


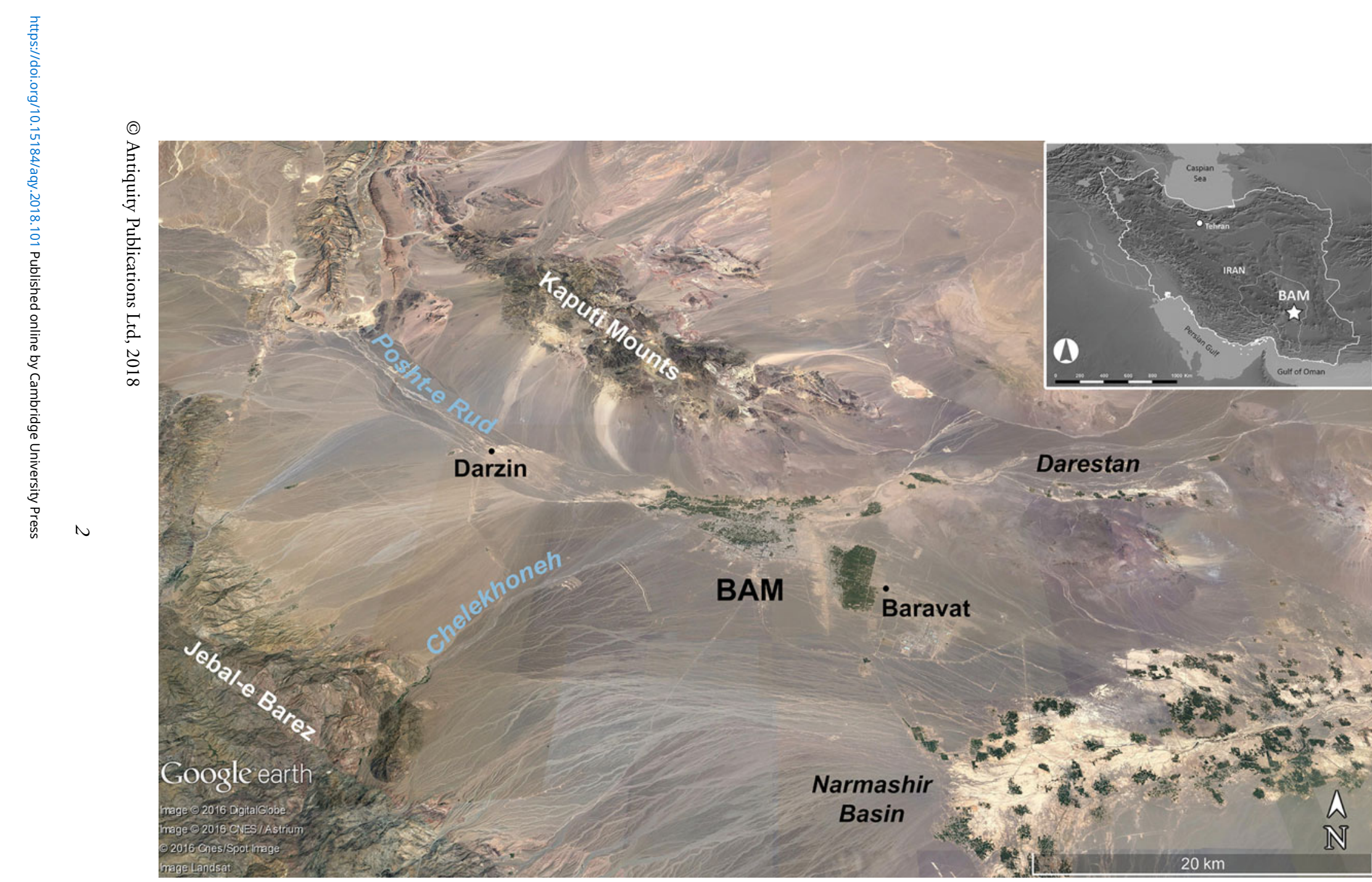

Figure 1. Satellite image of the Bam-Narmashir region showing the location of Bam city and the 2016 survey area between Darzin and Darestan (@ Google Earth). 


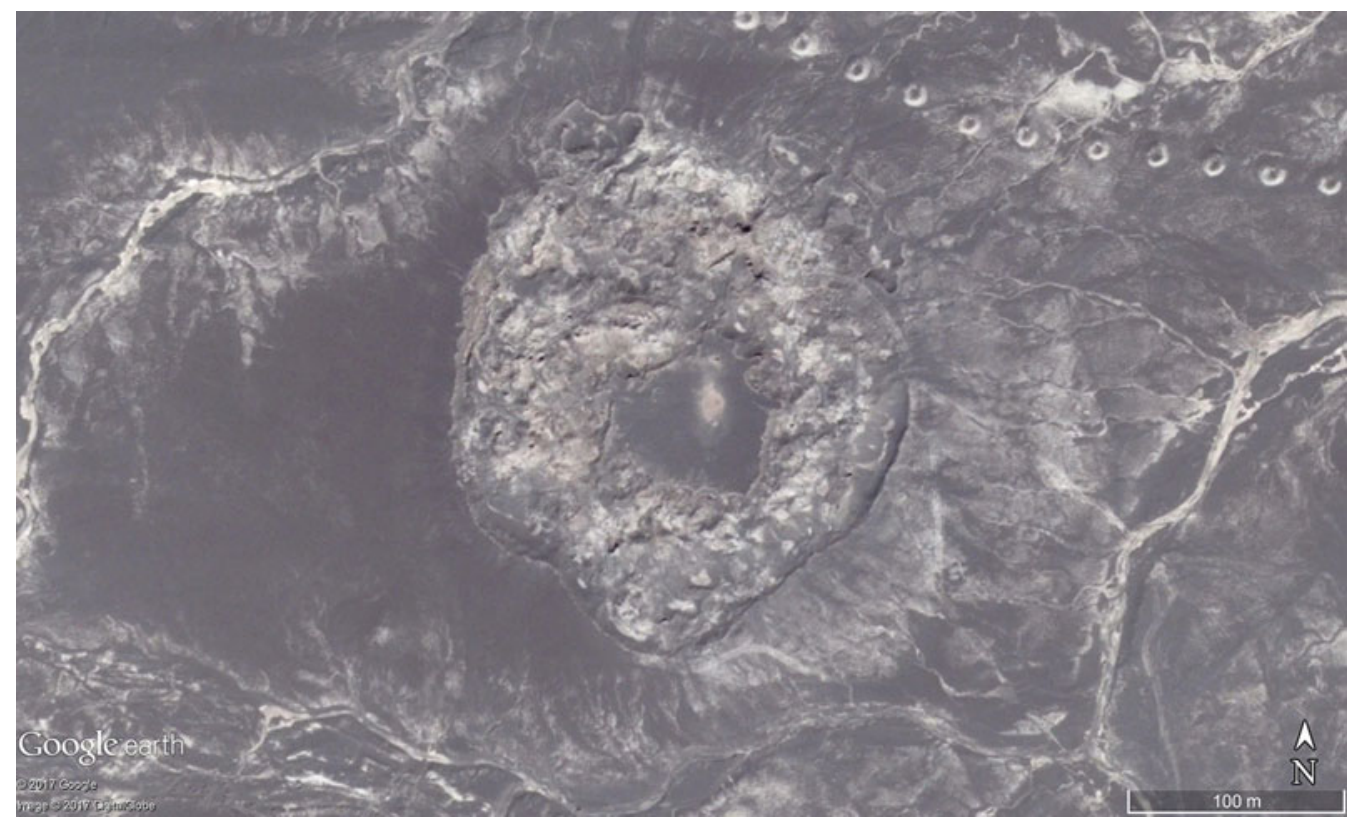

Figure 2. Satellite image of Tell-e Atashi (@) Google Earth).

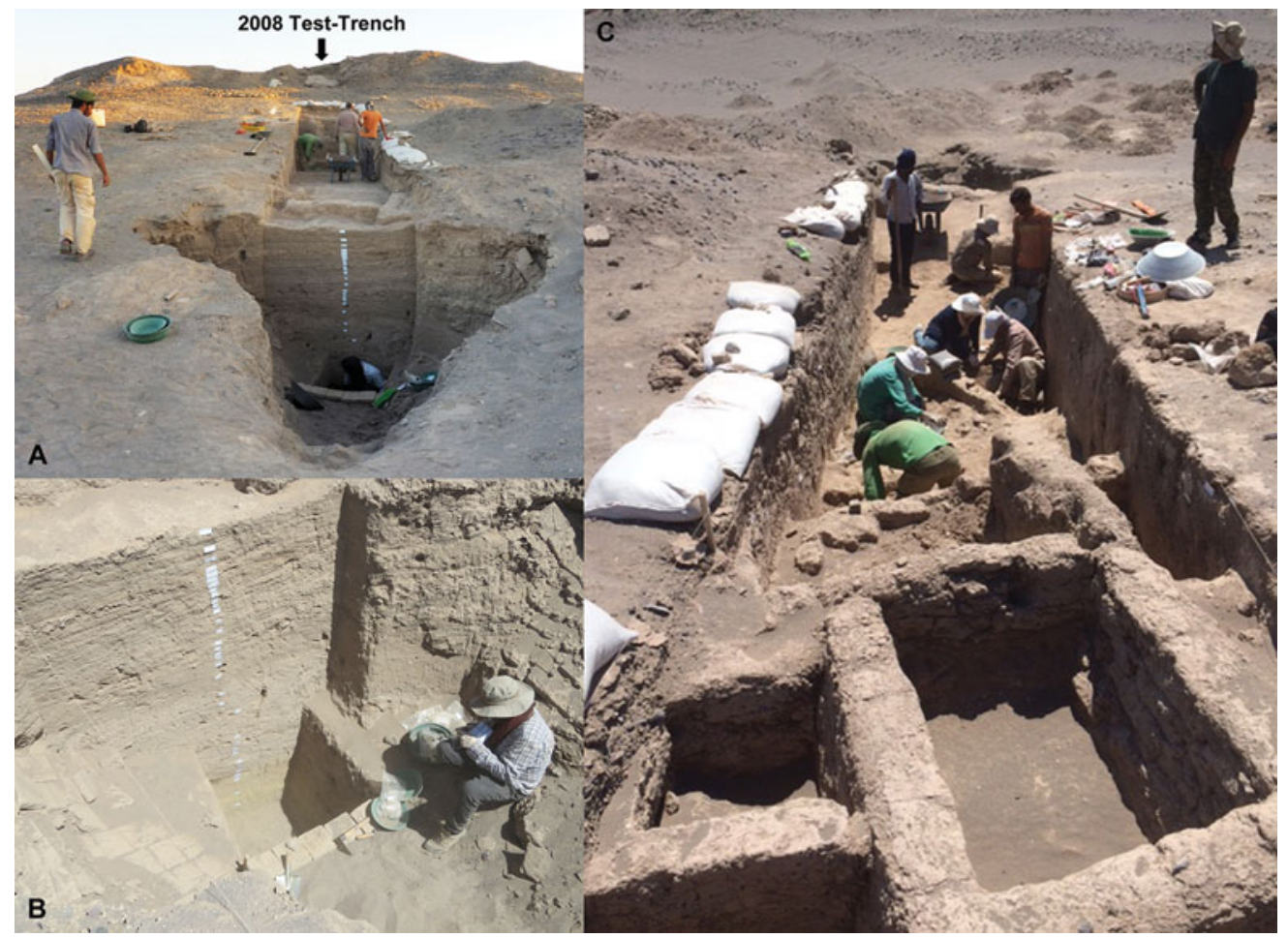

Figure 3. Tell-e Atashi trench: A) view from the south with the 2008 test trench in the background; B) view of the deep sounding in the southern part of the trench; $C$ ) view from the north of the trench and the mud-brick structures close to the surface in the foreground (@ BAM).

(C) Antiquity Publications Ltd, 2018 


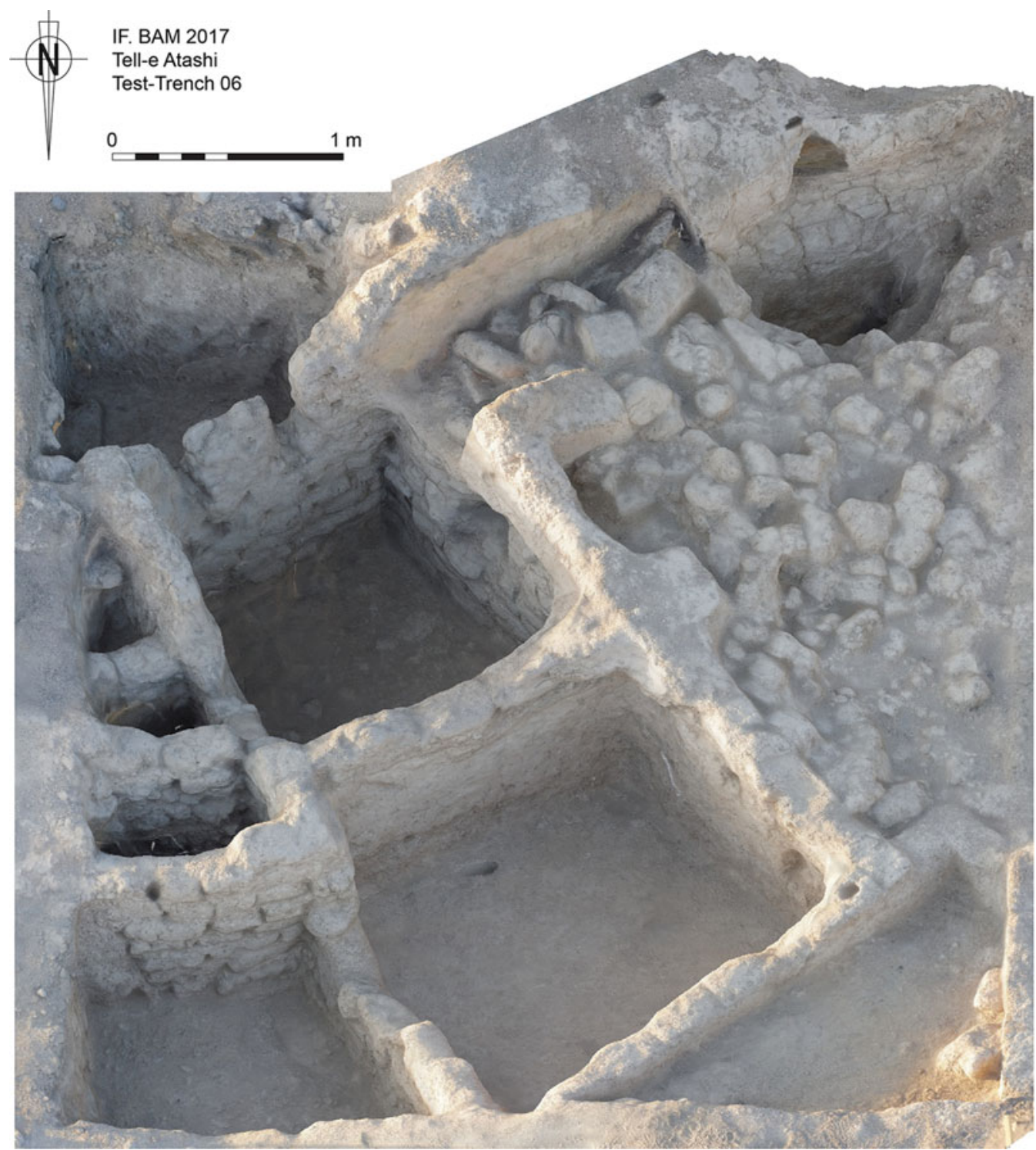

Figure 4. Tell-e Atashi, mud-brick building in test trench 6 (C) BAM, 3D model created by O. Nasrabadi).

approximately $170 \mathrm{~km}$ to the south-west (Beale \& Lamberg-Karlovsky 1986). Around 10 Early Chalcolithic sites (mid to late fifth to early fourth millennia BC) were also discovered, their typical surface material comprising fine, painted ceramics named Black-on-buff ware and Black-on-red ware. These particular ceramics are also reported in both Kerman and Seistan-and-Balochistan Provinces, including from Tal-i Iblis (periods I-II), Shahdad, Tepe Yahya (period V) and the Bampur Valley (Caldwell 1967; Beale \& Lamberg-Karlovsky 1986; see also Mutin et al. 2017).

(C) Antiquity Publications Ltd, 2018 


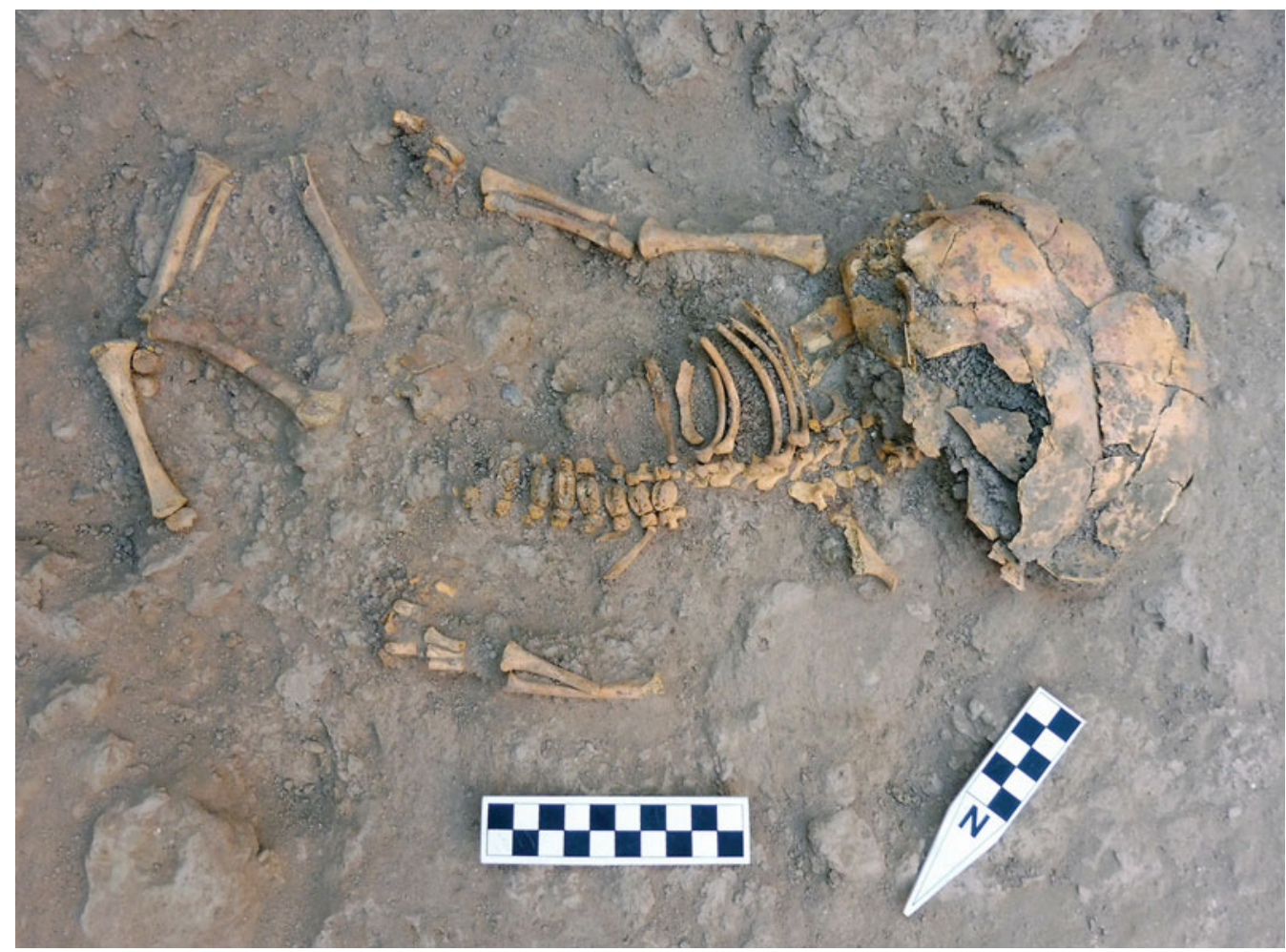

Figure 5. Tell-e Atashi, child burial in test trench 6 (@ BAM).

The Bam region is then marked by an increase in local occupation, represented by approximately 70 Late Chalcolithic sites dating to the rest of the fourth millennium BC. Their surface material includes a painted ceramic named Aliabad ware, which is reported from additional sites in south-eastern Iran, including Tal-i Iblis (period IV), and southwestern Pakistan (Caldwell 1967; see also Mutin et al. 2017). The Aliabad settlements in Bam include sites with ceramic kilns and misfired fragments. The Bronze Age, then, saw a sharp decrease in occupation, characterised by sparse third-millennium BC material; Bronze Age Bam so far lacks the typical, fine mineral-tempered, painted ceramics and chlorite objects, as well as the high site density and large settlements that characterise the Halil Rud Valley (approximately $90 \mathrm{~km}$ to the south-west) during this period (Madjidzadeh \& Pittman 2008). Finally, we observed few sites with Iron Age/early historical materials, although sites with ceramics relating to the Iron Age through to the Parthian period (c. first millennium $\mathrm{BC}$ to $224 \mathrm{AD}$ ) are present south of Bam city (Adle 2006: 45-46; Figure 1: west of Baravat).

\section{Second field season}

In 2017, we resumed excavation at Tell-e Atashi. The mounded part of this site covers approximately 3.6ha and is the largest Neolithic site recorded in the Bam region (Figure 2). A trench opened in 2008 revealed levels with square mud-brick structures radiocarbon dated to between the late sixth and mid fifth millennia BC, with associated lithics and small finds, 

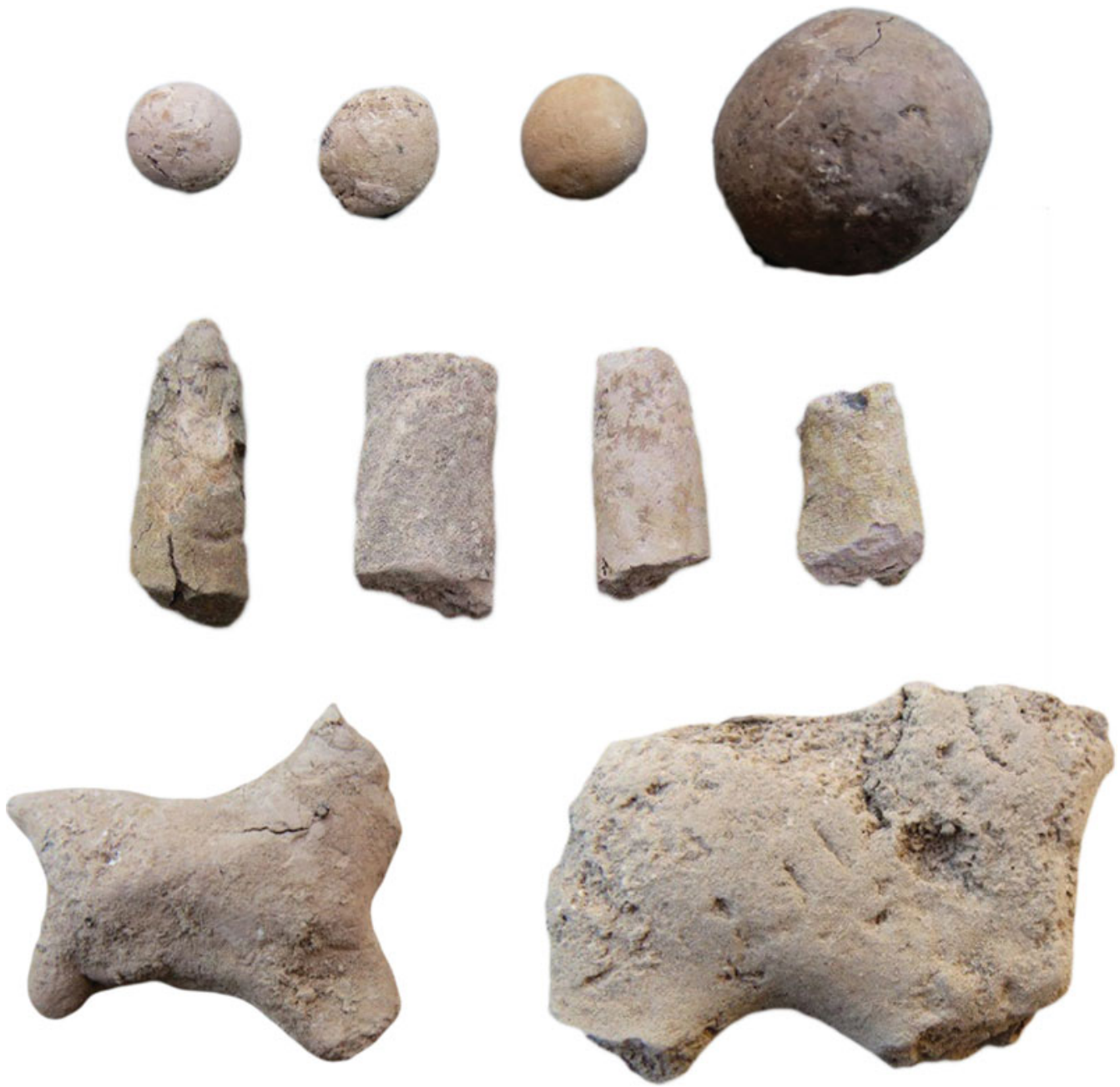

\section{0}

\section{$50 \mathrm{~mm}$}

Figure 6. Tell-e Atashi, selection of clay objects: balls (upper row), cones (middle row) and figurines (lower row) (@ BAM).

but no ceramics (Garazhian 2009). This information, combined with the critical location of Tell-e Atashi between the Fertile Crescent and South Asia, prompted us to resume fieldwork at this site. Fieldwork at Tell-e Atashi has great potential for both improving our understanding of the southern Iranian Neolithic and providing new research data and models for the development of farming across Iran and South Asia.

Our goals for 2017 were to gather further information on the stratigraphy, chronology and spatial organisation of this site, before planning more extensive future excavations. We opened a new trench — which aligned with the 2008 test trench (Figure 3) —as well as seven (C) Antiquity Publications Ltd, 2018 
additional test trenches in other areas of the site. In the first trench, we exposed the earliest archaeological deposits and sterile soil almost nine metres below ground surface at the top of the site (Figure $3 \mathrm{~A} \& \mathrm{~B}$ ). In the upper part of this trench (close to the surface), we discovered mud-brick structures similar to those excavated in 2008 (Figure 3C).

Approximately $75 \mathrm{~m}$ farther north, we excavated a well-preserved mud-brick building (Figure 4), in which a child burial was placed after the area was abandoned (Figure 5). The material culture at Tell-e Atashi comprises lithics, stone vessels, beads and perforated discs, as well as clay balls, cones and figurines (Figure 6). Some of these objects, as with the mud-bricks used for construction, have parallels at Tepe Yahya. In contrast to Tell-e Atashi, however, Tepe Yahya yielded ceramics from its earliest Neolithic levels (Beale \& Lamberg-Karlovsky 1986).

\section{Acknowledgements}

The BAM is a cooperative project between the Iranian Center for Archaeological Research, the Iran Research Institute for Cultural Heritage and Tourism, the French National Center for Scientific Research (CNRS-UMR 7041, Archéologies et Sciences de l'Antiquité, Archéologie de l'Asie centrale) and the French Ministry for Europe and Foreign Affairs. The authors also appreciate the support provided by the Kerman Province Cultural Heritage Tourism and Handicrafts Organization and the Arg-e Bam Research Foundation.

\section{References}

AdLE, C. 2006. Qanats of Bam: an archaeological perspective. Irrigation system in Bam, its birth and evolution from the prehistoric period up to modern times, in N. Honari, A. Salamat, A. Salih, J. Sutton \& J. Taniguchi (ed.) Qanats of Bam. A multidisciplinary approach: 33-85. Tehran: UNESCO Tehran Cluster Office.

Beale, T.W. \& C.C. Lamberg-Karlovsky (ed.). 1986. Excavations at Tepe Yahya, Iran, 1967-1975. The early periods (American School of Prehistoric Research Bulletin 38). Cambridge (MA): Peabody Museum of Archaeology and Ethnology, Harvard University.

Caldwell, J. (ed.). 1967. Investigations at Tal-i Iblis (Illinois State Museum Preliminary Reports 9). Springfield: Illinois State Museum Society.
Garazhian, O. 2009. Darestan: a group of Pre-Pottery Neolithic (PPN) sites in south-eastern Iran. Antiquity Project Gallery 83(319). Available at: http://www.antiquity.ac.uk/projgall/garazhian319/ (accessed 18 May 2018).

Madjidzadeh, Y. \& H. Pittman. 2008. Excavations at Konar Sandal in the region of Jiroft in the Halil Basin: first preliminary report (2002-2008). Iran 46: 69-103.

Mutin, B., H. Moradi, H. Sarhaddi-Dadian, H. Fazeli Nashli \& M. Soltani. 2017. New discoveries in the Bampur Valley (south-eastern Iran) and their implications for the understanding of settlement pattern in the Indo-Iranian borderlands during the Chalcolithic period. Iran 55: 99-119. https://doi.org/10.1080/05786967.2017.1356004

Soleimani, N.A., M. Shafiee, N. Eskandari $\&$ H.M. SAlehi. 2016. Khaje Askar: a $4^{\text {th }}$-millennium BC cemetery in Bam, south-eastern Iran. Iranica Antiqua 51: 57-84. 